\title{
Effect of loading dose of atorvastatin therapy prior to percutaneous coronary intervention in patients with acute coronary syndrome: a meta-analysis of six randomized controlled trials
}

This article was published in the following Dove Medical Press journal:

Drug Design, Development and Therapy

\begin{abstract}
Mingfeng Ma, ${ }^{1,2}$ Lixia Bu, ${ }^{3}$ Li Shi,' Renwei Guo, ${ }^{3}$ Bin Yang, ${ }^{2}$ Huili Cao, ${ }^{2}$ Liangping Luo, ${ }^{4}$ Ligong Lu ${ }^{5}$

'Department of Cardiology, Zhuhai Hospital Affiliated with Jinan University (Zhuhai People's Hospital), Zhuhai, Guangdong 5I9000, People's Republic of China; ${ }^{2}$ Department of Cardiovascular Medicine, Second Hospital of Shanxi University, Taiyuan, Shanxi 03000I, People's Republic of China; ${ }^{3}$ Department of Neurology, Fenyang Hospital of Shanxi Province, Fenyang, Shanxi 032200, People's Republic of China; ${ }^{4}$ Department of Medical Imaging Center, The First Affiliated Hospital of Jinan University, Guangzhou, Guangdong 5I0630, People's Republic of China; ${ }^{5}$ Center of Intervention Radiology, Zhuhai Precision Medicine Center, Zhuhai People's Hospital, Zhuhai, Guangdong 5 I9000, People's Republic of China
\end{abstract}

Correspondence: Ligong Lu Center of Intervention Radiology, Zhuhai Precision Medicine Center, Zhuhai People's Hospital, 79 Kangning Road, Zhuhai, Guangdong 519000, People's Republic of China

Tel +86I 38025 I 1398

Email mamingfeng106@sina.com

Liangping Luo

Department of Medical Imaging Center, The First Affiliated Hospital of Jinan University, 613 Huangpu West Road, Guangzhou, Guangdong 510630,

People's Republic of China

$\mathrm{Tel}+86$ I 3392692103

Email liangpingluo@।26.com

\begin{abstract}
Purpose: The study sought to summarize the evidence of pre-procedural atorvastatin therapy to improve the prognosis of acute coronary syndrome (ACS) patients undergoing percutaneous coronary intervention (PCI).

Patients and methods: We searched PubMed and Embase from inception to July 2018 for randomized controlled trials that compared loading dose atorvastatin pretreatment with no or low dose for the prevention of cardiovascular events. The primary end points were all-cause mortality and myocardial infarction (MI) at 30 days. The secondary end point was 30-day major adverse cardiovascular events (MACE), a composite of all-cause mortality, MI, and revascularization.
\end{abstract}

Results: Six trials with 4,991 individuals were included in our meta-analysis. High-dose atorvastatin preloading before PCI was associated with a $27 \%$ relative reduction in MI (OR: $0.73,95 \% \mathrm{CI}, 0.56-0.94, P=0.015$ ). All-cause mortality was nonsignificantly reduced by early treatment with high-potency atorvastatin (OR: $0.94,95 \%$ CI, $0.69-1.30, P=0.725$ ). There was a $20 \%$ reduction in MACE in the group of patients treated with statin loading prior to PCI (OR: $0.80,95 \% \mathrm{CI}, 0.66-0.97, P=0.026$ ). When stratified according to the diagnosis of ACS, the results of MACE were only significant for those ST-elevation myocardial infarction patients undergoing PCI (OR: $0.67,95 \% \mathrm{CI}, 0.48-0.94, P=0.022)$ and were not noted in the group of non-ST elevation ACS patients (OR: $0.65,95 \% \mathrm{CI}, 0.35-1.22, P=0.179$ ).

Conclusion: High-dose atorvastatin pretreatment leads to a significant reduction in $\mathrm{MI}$ and MACE at 30 days in ACS patients undergoing PCI, especially in ST-segment elevation MI.

Keywords: atorvastatin, acute coronary syndrome, percutaneous coronary intervention, adverse events

\section{Introduction}

The effect of a loading dose of statin, pretreatment before percutaneous coronary intervention (PCI), has been demonstrated in several observational studies and randomized controlled trials (RCTs) in the patients with acute coronary syndrome (ACS). ${ }^{1,2}$ Preloading with high-potency statins was associated with lower risk of adverse events, mainly due to a decreased rate of periprocedural myocardial infarction (MI) and revascularization..$^{3-5}$ The underlying mechanism of the benefit with statins was probably multifactorial and was hypothesized to be related to the complex pleiotropic effects of statins, which improve endothelial function, stabilize the atherosclerotic plaque, and decrease the vascular inflammation. ${ }^{6-8}$ Thus, current European and American guidelines 
recommend the administration of statins as early as possible in ACS patients, irrespective of cholesterol concentration at presentation. ${ }^{9,10}$

Long-term statin therapy has been shown to improve prognosis of patients with ACS. Yet it is less clear as to whether short-term high-dose atorvastatin pretreatment provides a consistent benefit in differential diagnosis of ACS patients, including ST-segment elevation MI (STEMI) and non-ST segment elevation acute coronary syndrome (NSTEACS), undergoing PCI. ${ }^{2}$ We therefore conducted a metaanalysis based on relevant and available RCTs to assess the efficacy of short-term high-dose atorvastatin pretreatment in patients with ACS undergoing PCI, especially among patients presenting with differential diagnosis.

\section{Materials and methods}

\section{Literature search and selection criteria}

The systematic review and meta-analysis were conducted and reported in adherence to PRISMA guidelines. ${ }^{11}$ Two researchers independently searched the published articles in the PubMed and Embase for the effect of high-dose atorvastatin preloading before PCI in ACS patients. Relevant keywords related to atorvastatin in combination with words related to "acute coronary syndrome" or "myocardial infarction" or "unstable angina" were searched. Our search was limited to articles published in English language only. The last search was run on July 11, 2018. Two independent investigators carried out the initial search, deleted duplicate records, screened the titles and abstracts for relevance, and identified as excluded or requiring further assessment. If there was a dispute between the investigators, it was solved through joint discussion or by taking the opinion of the third investigator. All the investigators had sufficient experience in meta-analysis, writing, and literature search. We also reviewed previous meta-analyses and the references of the selected studies.

Studies meeting the following inclusion criteria were included: 1) participatant: ACS patients undergoing PCI; 2) intervention: loading doses of atorvastatin (80 mg) therapy before PCI; 3) comparison: the control group was given placebo, lower dose atorvastatin therapy (10 mg or $20 \mathrm{mg}$ daily), or not receiving any atorvastatin before PCI; 4) outcome: major adverse cardiovascular end points (MACE); 5) study design: RCTs.

\section{Data extraction and quality assessment}

Data extraction was performed by MM and confirmed independently by LB. The following information was extracted from each study: the first author's name, year of publication, participants' characteristics, study design, total number of individuals, regimen of atorvastatin, type of controls (blank, placebo, or low dose of atorvastatin), prespecified clinical outcomes, and status of illness (unstable angina pectoris, STEMI, NSTEMI). Extracted data were entered into a standardized Excel file. Discrepancies were resolved by discussion between the two investigators and if the authors could not reach a consensus, disagreements were resolved by the third author (BY). The primary outcomes were allcause mortality and MI at 30 days. The secondary outcome was 30-day MACE, stratified by STEMI and NSTE-ACS. The bias risk of trials was assessed with the components recommended by the Cochrane Collaboration, ${ }^{12}$ including sequence generation of the allocation, allocation concealment, blinding of participants, personnel and outcome assessors, incomplete outcome data, selective outcome reporting, and other sources of bias.

\section{Statistical analysis}

Risk ratio (RR) with 95\% CIs was used to express the pooled effect on discontinuous variables. Heterogeneity across studies was tested by using the $I^{2}$ statistic, which was a quantitative measure of inconsistency across studies. Studies with an $I^{2}$ statistic of $25 \%-50 \%$ were considered to have low heterogeneity, those with an $I^{2}$ statistic of $50 \%-75 \%$ were considered to have moderate heterogeneity, and those with an $I^{2}$ statistic of $>75 \%$ were considered to have a high degree of heterogeneity. Fixed-effects meta-analyses were conducted to pool these outcomes across the included trials when there was no between-study inconsistency, whereas the random-effects model was used if heterogeneity existed.

Publication bias was evaluated using a funnel plot. All $P$-values were two-tailed, with statistical significance set at 0.05 , except where otherwise specified. All statistical analyses were performed using Stata 12.0 (Stata Corporation, College Station, TX, USA).

\section{Results \\ Characteristics of studies selected for meta-analysis}

The flow chart (Figure 1), describing the process of publication screening and the reasons for exclusion is shown in Figure 1. Of the 705 potentially relevant articles initially screened, a total of six RCTs ${ }^{2,13-17}$ including 4,991 individuals were selected. Among these, 2,483 patients were randomized to loading dose of atorvastatin pre-PCI and 2,508 patients comprised the control group. The characteristics of the 


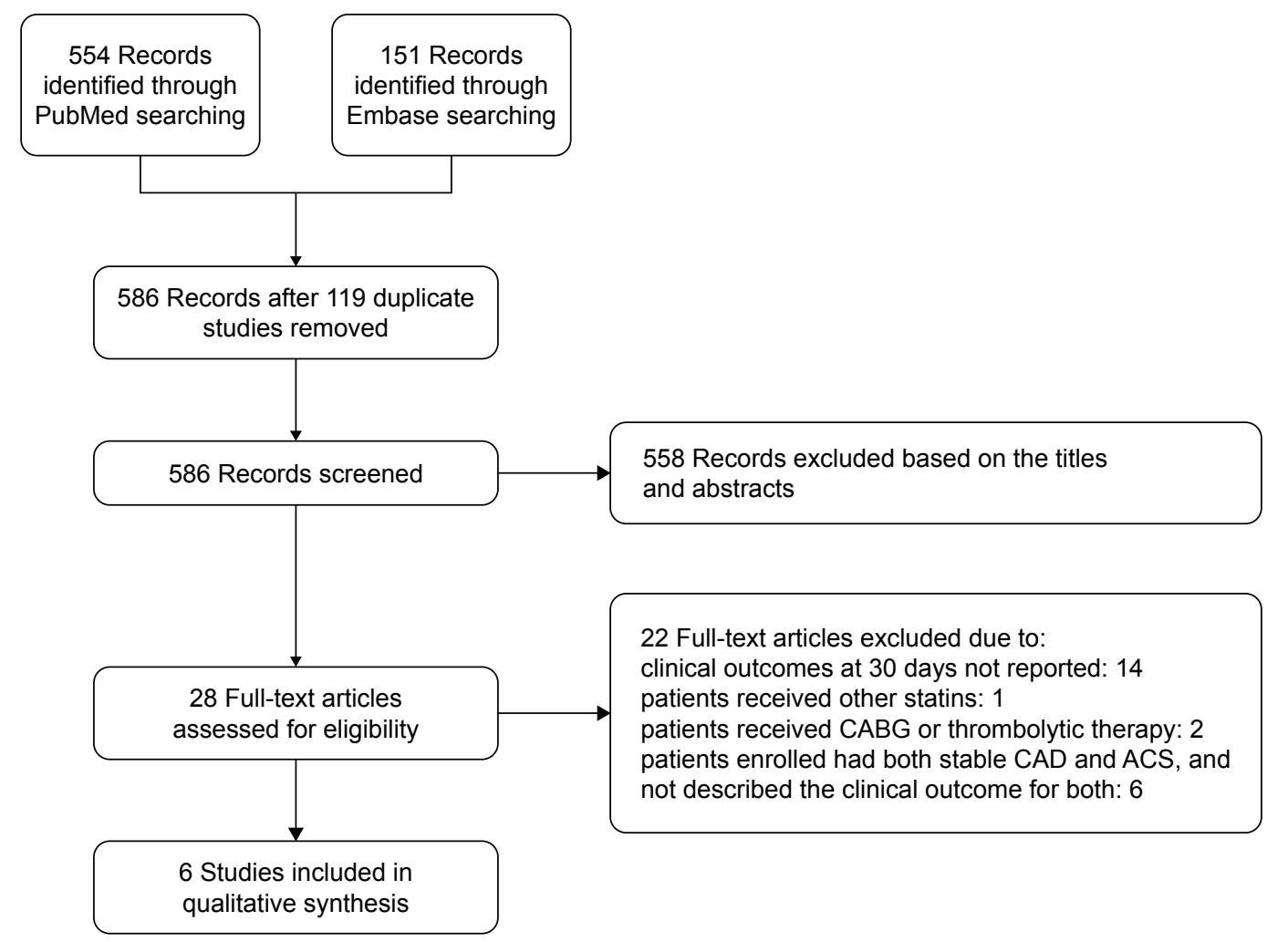

Figure I Flow diagram of study selection.

Abbreviations: CABG, coronary artery bypass grafting; CAD, coronary artery disease; ACS, acute coronary syndrome.

included trials are shown in Table 1. There were one enrolling patients with ACS, combination of STEMI and NSTE-ACS; two enrolling only STEMI; and three enrolling only NSTEACS among the six included trials.

\section{Assessment of the study quality}

The quality characteristics of included studies are provided in Table 2. All of the studies included patients with similar baseline characteristics and provided details about the

Table I Characteristics of the included studies

\begin{tabular}{|c|c|c|c|c|c|c|}
\hline Study & $\begin{array}{l}\text { Participants, } \\
\text { Expt/Ctrl }\end{array}$ & $\begin{array}{l}\text { Age, years, Expt/ } \\
\text { Ctrl }\end{array}$ & Male, n (\%), Expt/Ctrl & Diagnosis & Treatment & Outcomes \\
\hline $\begin{array}{l}\text { Berwanger et al, } \\
2018^{2}\end{array}$ & $1,351 / 1,359$ & $61.7 \pm 11.3 / 61.9 \pm 11.7$ & I,58I (75.8)/I,525 (72.5) & ACS & $\begin{array}{l}80 \mathrm{mg} \text { before } \mathrm{PCl} \text { vs } \\
\text { placebo }\end{array}$ & MACE at 30 days \\
\hline Jang et al, $2014^{13}$ & $163 / 172$ & $60 \pm 10 / 61 \pm 9.2$ & $116(71.2) / 126(73.3)$ & NSTE-ACS & $\begin{array}{l}80 \mathrm{mg} \text { at } 12 \text { hours }+ \\
40 \mathrm{mg} \text { at } 2 \text { hours } \\
\text { before } \mathrm{PCl} \text { vs no statin }\end{array}$ & MACE at 30 days \\
\hline Kim et al, $2010^{14}$ & $86 / 85$ & $61 \pm 11 / 59 \pm 11$ & $66(76.7) / 66(77.6)$ & STEMI & $\begin{array}{l}80 \mathrm{mg} \text { before } \mathrm{PCl} \text { vs } \\
10 \mathrm{mg} \text { before } \mathrm{PCl}\end{array}$ & MACE at 30 days \\
\hline Patti et al, $2007^{15}$ & $86 / 85$ & $64 \pm 11 / 67 \pm 10$ & $68(79) / 67(79)$ & NSTE-ACS & $\begin{array}{l}80 \mathrm{mg} \text { at } 12 \text { hours }+ \\
40 \mathrm{mg} \text { at } 2 \text { hours } \\
\text { before } \mathrm{PCl} \text { vs no statin }\end{array}$ & MACE at 30 days \\
\hline Post et al, 2012 $2^{16}$ & $20 / 22$ & $57.5 \pm 7.7 / 54.3 \pm 7.2$ & $19(86) / 13(65)$ & STEMI & $\begin{array}{l}80 \mathrm{mg} \text { before } \mathrm{PCl} \text { vs } \\
\text { no statin }\end{array}$ & $\begin{array}{l}\text { End-systolic volume } \\
\text { index (ESVI) at } \\
3 \text { months }\end{array}$ \\
\hline Yu et al, 20I I ${ }^{17}$ & $41 / 40$ & $63.3 \pm 10.5 / 64.4 \pm 11.6$ & $25(6 \mathrm{I}) / 23(58)$ & NSTE-ACS & $\begin{array}{l}80 \mathrm{mg} \text { at } 12 \text { hours + } \\
40 \mathrm{mg} \text { at } 2 \text { hours } \\
\text { before } \mathrm{PCl} \text { vs placebo }\end{array}$ & MACE at 30 days \\
\hline
\end{tabular}

Abbreviations: ACS, acute coronary syndrome; PCI, percutaneous coronary intervention; MACE, major adverse cardiovascular end points; MI, myocardial infarction; STEMI, ST-segment elevation MI; NSTE-ACS, non-ST segment elevation acute coronary syndrome; Expt, experiment; Ctrl, control. 
Table 2 Assessment of methodological quality of included studies

\begin{tabular}{|c|c|c|c|c|c|}
\hline Study & $\begin{array}{l}\text { Randomized } \\
\text { method }\end{array}$ & $\begin{array}{l}\text { Allocation } \\
\text { concealment }\end{array}$ & Blinded & $\begin{array}{l}\text { Withdrawals and } \\
\text { lost to follow-up }\end{array}$ & $\begin{array}{l}\text { Intent-to-treat } \\
\text { analysis }\end{array}$ \\
\hline $\begin{array}{l}\text { Berwanger et al, } \\
2018^{2}\end{array}$ & $\begin{array}{l}\text { Randomized block } \\
\text { design }\end{array}$ & Yes & Double blind & No & Yes \\
\hline Jang et al, $2014^{13}$ & Randomized unclear & Unclear & Open label & No & No \\
\hline Kim et al, $2010^{14}$ & $\begin{array}{l}\text { Randomization } \\
\text { sequence }\end{array}$ & Unclear & $\begin{array}{l}\text { Double blind (care } \\
\text { provider and assessor) }\end{array}$ & No & No \\
\hline Patti et al, $2007^{15}$ & $\begin{array}{l}\text { Randomized block } \\
\text { design }\end{array}$ & Unclear & Double blind & No & No \\
\hline Post et al, $2012^{16}$ & $\begin{array}{l}\text { Randomized block } \\
\text { design }\end{array}$ & Yes & Double blind & No & No \\
\hline Yu et al, $201 \mathrm{I}^{17}$ & Randomized unclear & Unclear & Double blind & No & No \\
\hline
\end{tabular}

eligible criteria and completeness of follow-up. Among the six trials, four trials reported the specific methods used for randomization. Of them, three trials used a block random approach and the other one used a random numbers table. Blinded methods were used in five trials, and all of which used a double-blind approach. Two trials described the allocation concealments in detail and one trial provided the intention-totreat analysis. None of the included studies had incomplete outcome data, selective reporting, and other sources of bias.

\section{Effect of loading dose of atorvastatin pretreatment on clinical outcome}

Four studies were included in the all-cause mortality analysis at 30 days, with an overall incidence of 3.0\% (70 of 2,356) in the loading dose of atorvastatin group and 3.1\% (75 of 2,383 ) in the control group. There was a nonsignificant trend toward all-cause mortality reduction in the loading dose of atorvastatin group (risk ratio [RR]: 0.94, 95\% CI, $0.69-1.30, P=0.73$; Figure 2A) using the fixed-effect model.

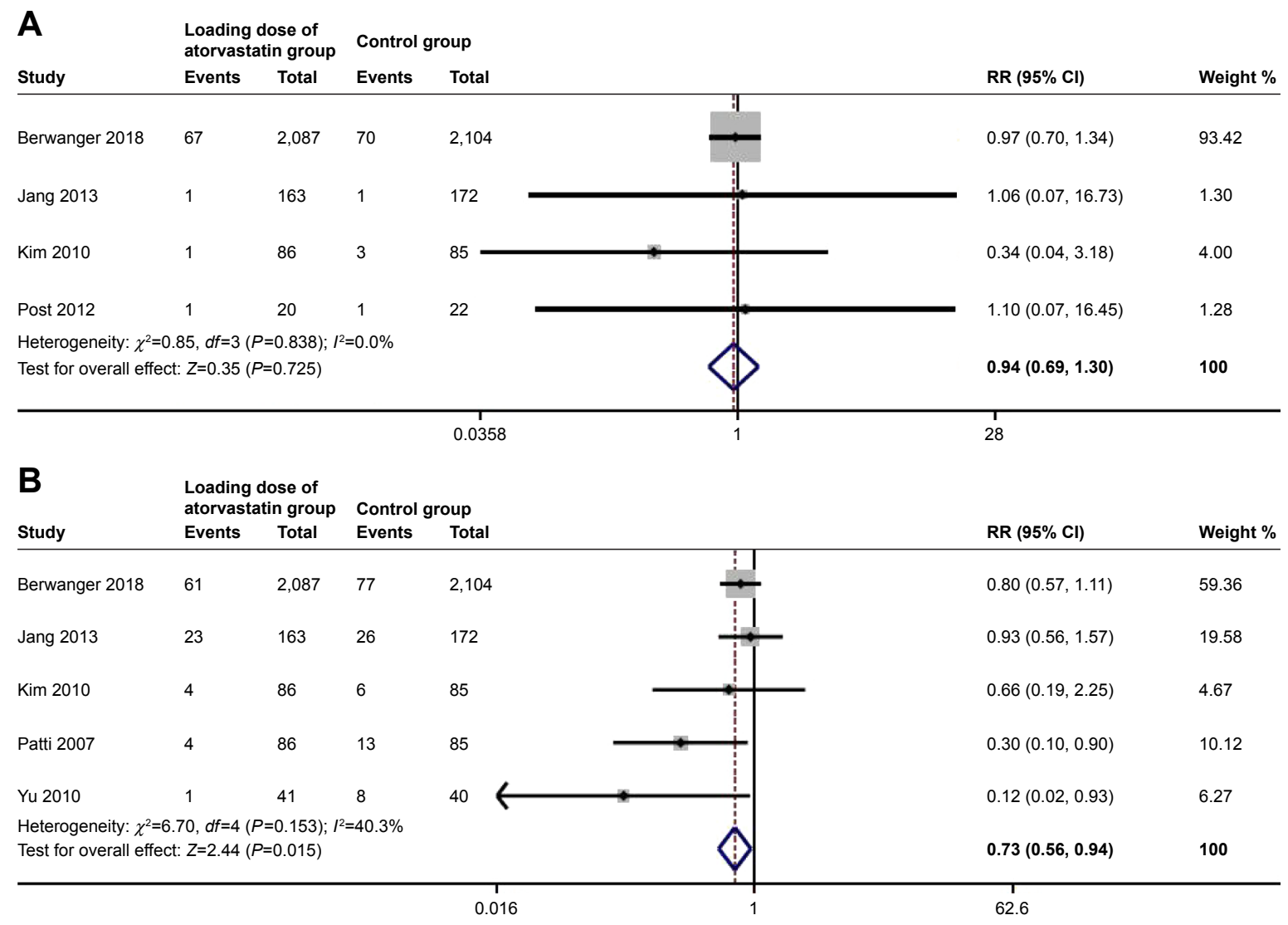

Figure 2 Pooled risk ratio (RR) of loading dose of atorvastatin pretreatment vs control for 30-day all-cause mortality (A) and myocardial infarction (B) after percutaneous coronary intervention. 
No significant heterogeneity was found between the two groups $\left(I^{2}=0.0 \%, P=0.84\right)$.

Outcome data for 30-day MI analysis were available from five trials. Compared with the control group, the high dose of atorvastatin group had significantly reduced incidence of $\mathrm{MI}$ (RR: $0.73,95 \%$ CI, $0.56-0.94, P=0.015$; Figure $2 \mathrm{~B}$ ) based on the fixed-effects model. There was no evidence of significant heterogeneity among these trials $\left(I^{2}=40.3 \%, P=0.15\right)$.

All the six studies reported the incidence of MACE. The overall incidence of MACE in the high dose of atorvastatin group was $6.7 \%$ (166 of 2,483), whereas in the control group, it was of $8.4 \%$ (210 of 2,508). The analysis showed that receiving high dose of atorvastatin pre-PCI was associated with a significantly lower MACE rate with a combined OR of 0.80 (95\% CI: 0.66-0.97, $P=0.026$ ) (Figure S1).

\section{Analysis of subgroups with differential diagnoses of ACS}

To determine whether the outcome of high-dose statin treatment prior to PCI was consistent in patients with differential diagnoses of ACS, including STEMI and NSTE-ACS, we assessed subgroups of patients according to their disease classification.

For the subgroup with STEMI, the incidence of MACE was significantly lower in the high-dose atorvastatin group than in the control group (OR: 0.67, 95\% CI, 0.48-0.94, $P=0.022 ; I^{2}=0.0 \%, P=0.81$ ) (Figure 3A); however, for patients with NSTE-ACS, there was no significant difference in MACE between the high-dose atorvastatin group and the control group (OR: 0.65, 95\% CI, 0.35-1.22, $\left.P=0.179 ; I^{2}=68.7 \%, P=0.022\right)$ by using the randomized model (Figure 3B).

\section{Publication bias}

As shown in Figure 4, the results did not provide any evidence of potential publication bias based on funnel plots and Egger's regression test. Funnel plots constructed using a fixed-effect model for all-cause mortality $(P=0.549$, Figure 4A) and MI ( $P=0.107$, Figure 4B) are presented.

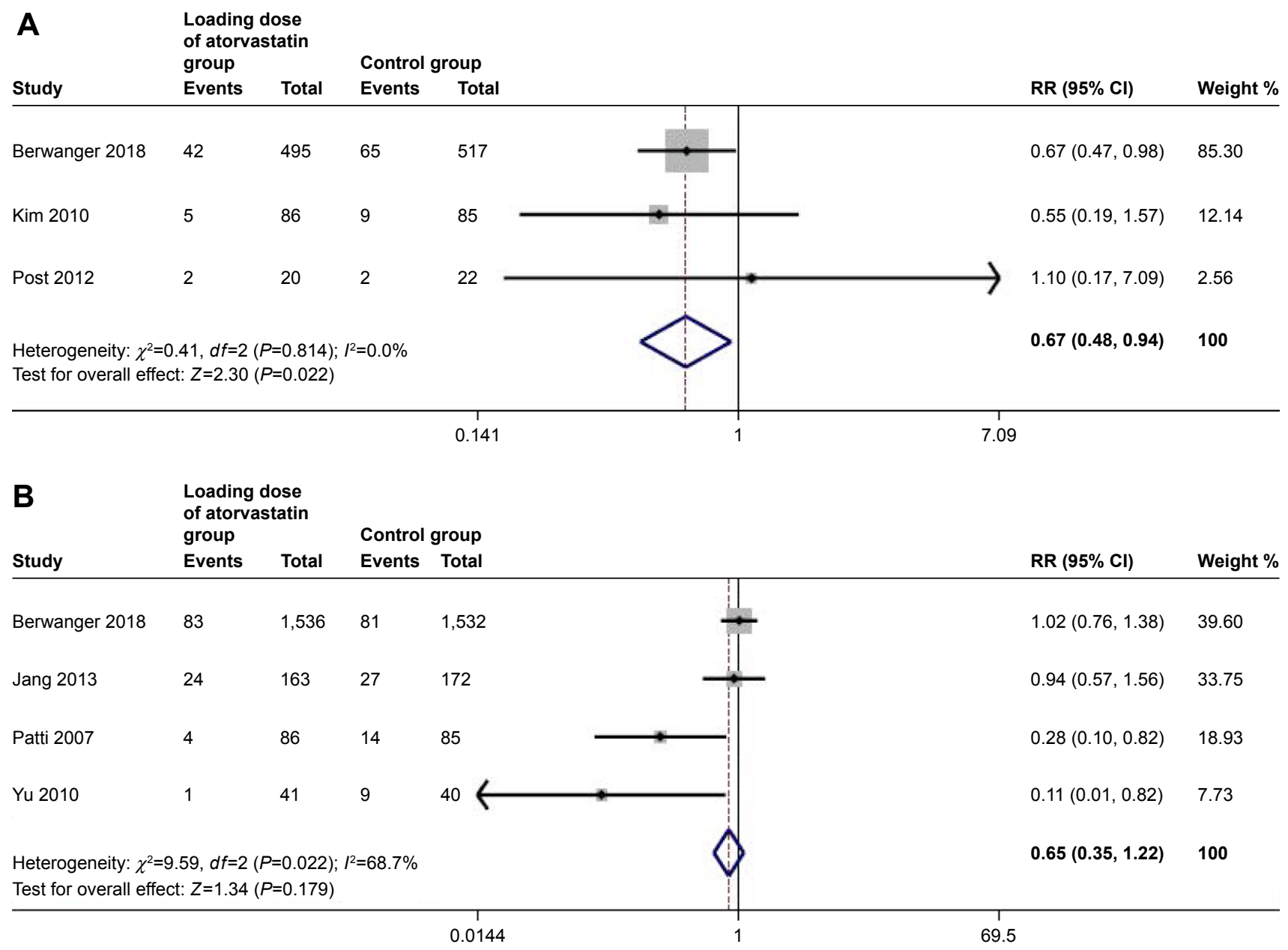

Figure 3 Subgroup analysis of forest plot of risk ratio (RR) and 95\% Cl for 30-day major adverse composite end point in patients with STEMI (A) and NSTE-ACS (B). Abbreviations: STEMI, ST-segment elevation myocardial infarction; NSTE-ACS, non-ST segment elevation acute coronary syndrome. 
A

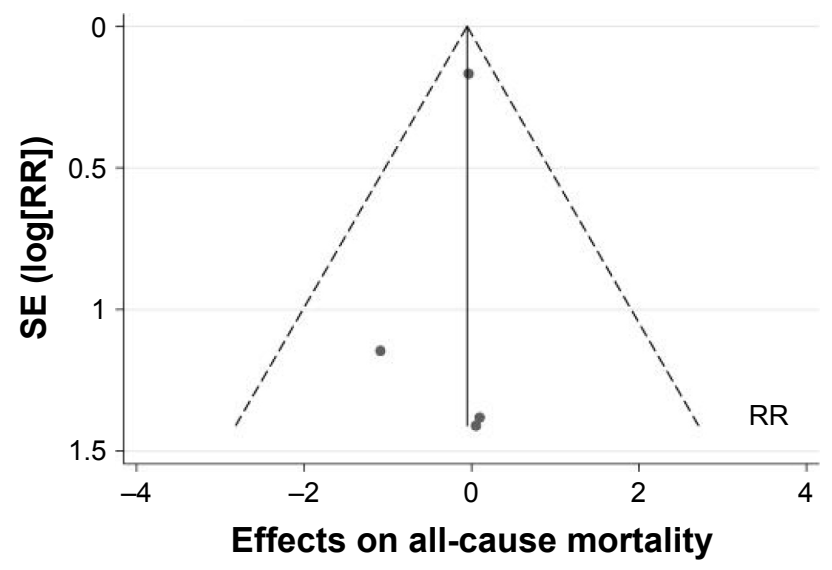

B

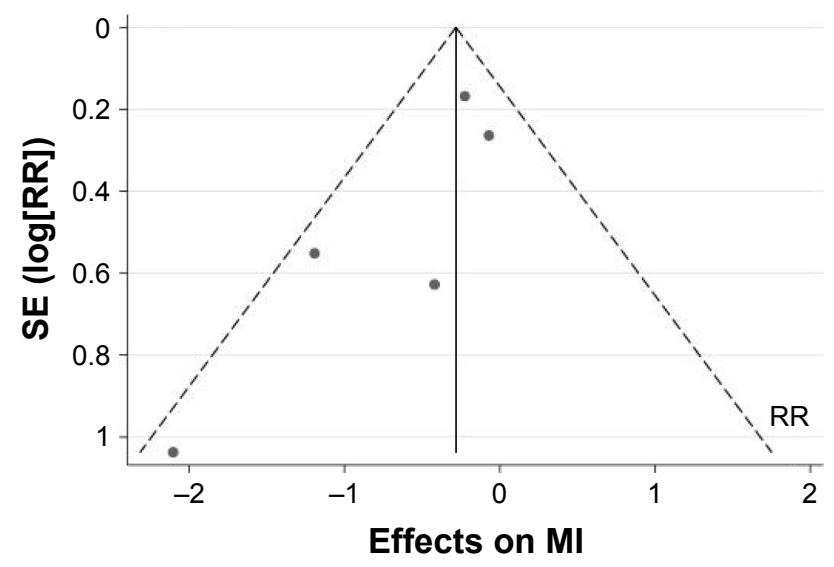

Figure 4 Funnel plot of included studies for all-cause mortality $(\mathbf{A})$ and myocardial infarction (B). Abbreviations: RR, risk ratio; MI, myocardial infarction.

\section{Discussion}

The current study, which included 4,991 individuals from six RCTs, mainly demonstrated that: 1) atorvastatin preloading in ACS patients undergoing PCI could significantly reduce the incidence of MI and MACE at 30 days; 2) the subgroup analysis showed that compared with the control group, STEMI patients receiving high dose of atorvastatin pre-PCI had a significant reduction in 30-day MACE, whereas in patients with NSTE-ACS there was no significant improvement between groups.

The beneficial effect of statin therapy has had a profound effect on ACS patients. Administration of statins prior to PCI might be of benefit, which is addressed by mechanistic studies demonstrating that it is anti-inflammatory and has favorable effects on platelet reactivity, circulating markers of myonecrosis, and microvascular obstruction, besides a lipid-lowering effect. ${ }^{6}, 18,19$ Nevertheless, there was no significant difference in the 30-day rate of all-cause mortality. Previous trials demonstrated that the loading dose of statin could improve some "surrogate" measures, such as infarct size or specific biomarkers, ${ }^{17,20,21}$ which might decrease the adverse events in the long term logically. However, as the most "hard" end point, mortality might be very hard to decline significantly by improving endothelial function and myocardial circulation during limited period (30 days), which could explain to some extent why no studies show a positive result about this outcome. The present study confirmed that the loading doses of atorvastatin might have a role in reducing the risk of MI in ACS patients undergoing PCI, which might mainly be driven by a decreased rate of periprocedural MI., ${ }^{3,422}$ Meanwhile, the benefit of early protective effects of high-dose atorvastatin, attributed to its multifactorial effects mentioned previously, might be responsible for the improved clinical outcomes observed after PCI.

Moreover, in order to identify potential differences in treatment across the patients, subgroup analysis revealed that the clinical benefit of high-dose atorvastatin pretreatment was significant in STEMI patients, but not in NSTE-ACS patients.

A previous meta-analysis demonstrated a $68 \%$ reduction in short-term clinical events when statin therapy is given as a loading dose prior to PCI in NSTE-ACS patients. ${ }^{23}$ However, the results should be interpreted with caution, such as the rates of 30-day MACE in stable and NSTE-ACS patients (14.0\% vs $3.3 \%$, respectively) during the follow-up period. The higher incidence of stable patients in the pool analysis with a 45 months follow-up period ${ }^{24}$ should be the main responsibility for the reduction of MACE in NSTE-ACS patients.

Currently, a series of lipid-lowering trials have supported the concept "the lower, the better". Moreover, guidelines have already suggested that ACS patients should receive high-intensity statin therapy. The strategy which involves administering high doses of statin within the first 24 hours is likely to be beneficial for both prevention of subsequent cardiovascular events and increased long-term adherence to statin therapy, which is a cornerstone of secondary prevention. Just like Statins Evaluation in Coronary procedures and Revascularization (SECURE-PCI) trial, the present study might present new management approach in terms of immediate statin administration in the emergency department to help clinicians make a more appropriate decision. In ACS patients, the strategy should be "the earlier, the lower, and the longer, the better".

The present study has several limitations. First, in our analysis, we limited major adverse cardiac events to 
true clinical end points and included only death, MI, and revascularization in a short-term follow-up, and therefore determining the long-term prognosis of ACS patients would be difficult. Further large clinical trials may provide better results in this regard. Another limitation is that the included studies used different therapy strategies for administration of atorvastatin (high loading dose vs placebo, no treatment, or low dose). Moreover, SECURE-PCI trial did not report the detailed outcome at 30-day follow-up period stratified by diagnosis of ACS, and hence we could not analyze every component of MACE in STEMI and NSTE-ACS subgroups. Finally, the number of articles finally included in the study was small and there may be a possibility for geographical bias.

\section{Conclusion}

Among ACS patients undergoing PCI, pre-procedural loading doses of atorvastatin could reduce the rate of $\mathrm{MI}$ and MACE at 30 days. This strategy might be beneficial for STEMI patients undergoing an invasive strategy. Nevertheless, further trials are needed to identify patients who might receive maximum benefit from preloading with high-potency statins.

\section{Disclosure}

The authors report no conflicts of interest in this work.

\section{References}

1. Schwartz GG, Ganz P, Waters D, Arikian S. Pharmacoeconomic evaluation of the effects of atorvastatin on early recurrent ischemic events in acute coronary syndromes. Am J Cardiol. 2003;92:1109-1112.

2. Berwanger O, Santucci EV, de Barros E Silva PGM, et al. Effect of loading dose of atorvastatin prior to planned percutaneous coronary intervention on major adverse cardiovascular events in acute coronary syndrome: the SECURE-PCI randomized clinical trial. JAMA. 2018;319:1331-1340. doi:10.1001/jama.2018.2444

3. Patti G, Cannon CP, Murphy SA, et al. Clinical benefit of statin pretreatment in patients undergoing percutaneous coronary intervention: a collaborative patient-level meta-analysis of 13 randomized studies. Circulation. 2011;123:1622-1632. doi:10.1161/CIRCULATIONAHA. 110.002451

4. Winchester DE, Wen X, Xie L, Bavry AA. Evidence of pre-procedural statin therapy a meta-analysis of randomized trials. J Am Coll Cardiol. 2010;56:1099-1109. doi:10.1016/j.jacc.2010.04.023

5. Gibson CM, Pride YB, Hochberg CP, et al. Effect of intensive statin therapy on clinical outcomes among patients undergoing percutaneous coronary intervention for acute coronary syndrome. PCI-PROVE IT: a PROVE IT-TIMI 22 (Pravastatin or atorvastatin evaluation and infection therapy-thrombolysis in myocardial infarction 22) substudy. J Am Coll Cardiol. 2009;54:2290-2295. doi:10.1016/j.jacc.2009.09.010

6. Eisen A, Leshem-Lev D, Yavin H, et al. Effect of high dose statin pretreatment on endothelial progenitor cells after percutaneous coronary intervention (HIPOCRATES study). Cardiovasc Drugs Ther. 2015;29: 129-135. doi:10.1007/s10557-015-6575-8

7. Davignon J. Beneficial cardiovascular pleiotropic effects of statins. Circulation. 2004;109:III39-III43. doi:10.1161/01.CIR.0000131517. 20177.5a
8. Rosenson RS, Tangney CC. Antiatherothrombotic properties of statins: implications for cardiovascular event reduction. JAMA. 1998;279: 1643-1650.

9. Ibanez B, James S, Agewall S, et al. 2017 ESC guidelines for the management of acute myocardial infarction in patients presenting with ST-segment elevation: the task force for the management of acute myocardial infarction in patients presenting with ST-segment elevation of the European Society of Cardiology (ESC). Eur Heart J. 2018;39: 119-177. doi:10.1093/eurheartj/ehx393

10. Amsterdam EA, Wenger NK, Brindis RG, et al. 2014 AHA/ACC guideline for the management of patients with Non-ST-Elevation acute coronary syndromes: a report of the American College of Cardiology/ American Heart Association Task Force on Practice Guidelines. J Am Coll Cardiol. 2014;64(24):e139-e228. doi:10.1016/j.jacc.2014.09.017

11. Moher D, Liberati A, Tetzlaff J, Altman DG. Preferred reporting items for systematic reviews and meta-analyses: the PRISMA statement. J Clin Epidemiol. 2009;62:1006-1012. doi:10.1016/j.jclinepi.2009.06.005

12. Higgins J, Green S. Cochrane Handbook for Systematic Reviews of Interventions. Oxford (UK): Cochrane Collaboration; 2008.

13. Jang Y, Zhu J, Ge J, Kim Y-J, Ji C, Lam W. Preloading with atorvastatin before percutaneous coronary intervention in statin-naive Asian patients with non-ST elevation acute coronary syndromes: a randomized study. J Cardiol. 2014;63:335-343. doi:10.1016/j.jjcc.2013.09.012

14. Kim JS, Kim J, Choi D, et al. Efficacy of high-dose atorvastatin loading before primary percutaneous coronary intervention in ST-segment elevation myocardial infarction: the STATIN STEMI trial. JACC Cardiovasc Interv. 2010;3:332-339. doi:10.1016/j.jcin.2009.11.021

15. Patti G, Pasceri V, Colonna G, et al. Atorvastatin pretreatment improves outcomes in patients with acute coronary syndromes undergoing early percutaneous coronary intervention: results of the ARMYDA-ACS randomized trial. J Am Coll Cardiol. 2007;49:1272-1278. doi:10.1016/j. jacc.2007.02.025

16. Post S, Post MC, van den Branden BJ, et al. Early statin treatment prior to primary PCI for acute myocardial infarction: REPERATOR, a randomized placebo-controlled pilot trial. Catheter Cardiovasc Interv. 2012;80:756-765. doi:10.1002/ccd.23449

17. Yu XL, Zhang HJ, Ren SD, et al. Effects of loading dose of atorvastatin before percutaneous coronary intervention on periprocedural myocardial injury. Coron Artery Dis. 2011;22:87-91. doi:10.1097/MCA. 0b013e328341baee

18. Wang CY, Liu PY, Liao JK. Pleiotropic effects of statin therapy: molecular mechanisms and clinical results. Trends Mol Med. 2008;14:37-44. doi:10.1016/j.molmed.2007.11.004

19. Nohria A, Prsic A, Liu PY, et al. Statins inhibit Rho kinase activity in patients with atherosclerosis. Atherosclerosis. 2009;205:517-521. doi:10.1016/j.atherosclerosis.2008.12.023

20. Shimomura M, Oyama J, Takeuchi M, et al. Acute effects of statin on reduction of angiopoietin-like 2 and glyceraldehyde-derived advanced glycation end-products levels in patients with acute myocardial infarction: a message from SAMIT (Statin for Acute Myocardial Infarction Trial). Heart Vessels. 2016;31:1583-1589. doi:10.1007/s00380-015-0773-y

21. Hahn JY, Kim HJ, Choi YJ, et al. Effects of atorvastatin pretreatment on infarct size in patients with ST-segment elevation myocardial infarction undergoing primary percutaneous coronary intervention. Am Heart J. 2011;162:1026-1033. doi:10.1016/j.ahj.2011.08.011

22. Wang L, Peng $\mathrm{P}$, Zhang $\mathrm{O}$, et al. High-dose statin pretreatment decreases periprocedural myocardial infarction and cardiovascular events in patients undergoing elective percutaneous coronary intervention: a meta-analysis of twenty-four randomized controlled trials. PLoS One. 2014;9:e113352. doi:10.1371/journal.pone.0113352

23. Benjo AM, El-Hayek GE, Messerli F, et al. High dose statin loading prior to percutaneous coronary intervention decreases cardiovascular events: a meta-analysis of randomized controlled trials. Catheter Cardiovasc Interv. 2015;85:53-60. doi:10.1002/ccd.25302

24. Veselka J, Zemanek D, Hajek P, et al. Effect of two-day atorvastatin pretreatment on long-term outcome of patients with stable angina pectoris undergoing elective percutaneous coronary intervention. Am J Cardiol. 2011;107:1295-1299. doi:10.1016/j.amjcard.2010.12.040 


\section{Supplementary material}

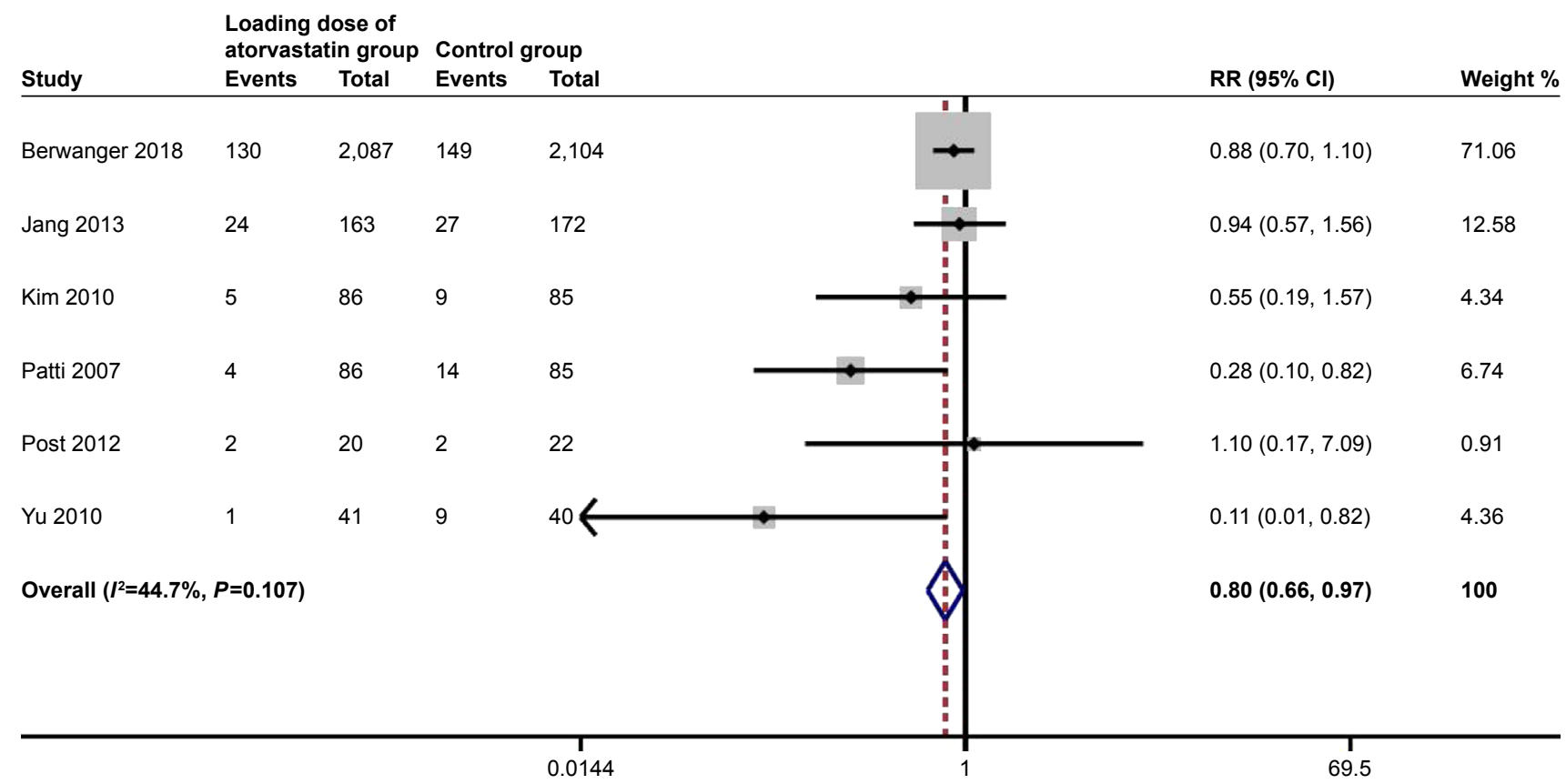

Figure SI Pooled risk ratio (RR) of loading dose of atorvastatin pretreatment vs control for 30-day major adverse composite end points after percutaneous coronary intervention.

\section{Publish your work in this journal}

Drug Design, Development and Therapy is an international, peerreviewed open-access journal that spans the spectrum of drug design and development through to clinical applications. Clinical outcomes, patient safety, and programs for the development and effective, safe, and sustained use of medicines are the features of the journal, which has also been accepted for indexing on PubMed Central. The manuscript management system is completely online and includes a very quick and fair peer-review system, which is all easy to use. Visit http://www.dovepress.com/testimonials.php to read real quotes from published authors.

Submit your manuscript here: http://www.dovepress.com/drug-design-development-and-therapy-journal 